\title{
Cancers among adolescents and young adults at one institution in Japan
}

\author{
KENSUKE KAMIMURA ${ }^{1,2}$, YOSHIFUMI MATSUMOTO ${ }^{1}$, QILIANG ZHOU ${ }^{1}$, \\ MASATO MORIYAMA ${ }^{1}$ and YASUO SAIJO ${ }^{1}$ \\ ${ }^{1}$ Department of Medical Oncology, Niigata University Graduate School of Medical and Dental Sciences, \\ Niigata 951-8510; ${ }^{2}$ Department of Pharmacy, Saiseikai Niigata Daini Hospital, Niigata 950-1104, Japan
}

Received May 14, 2018; Accepted September 25, 2018

DOI: $10.3892 / \mathrm{ol} .2018 .9535$

\begin{abstract}
Adolescents and young adults (AYAs) with cancer often live long lives following treatment and face many life events. No detailed studies of cancers in AYAs have described the epidemiology, treatment outcome, and social status in Japan. The present study defined AYAs as those aged 15-29 years old based on the US National Cancer Institute Surveillance, Epidemiology, and End Results (SEER) program. Data was collected from the hospital-based cancer registry and electronic medical charts at Niigata University Medical and Dental Hospital from 2007 to 2015. The present study analyzed the types of cancer, treatment methods and outcomes, fertility preservation, marital status, raising children, school admission, and employment status. A total of 362 (1.9\%) cancer cases in AYAs (males 119, females 243) were identified. Carcinoma was the most common type of cancer in both sexes. Females had a high incidence of carcinoma of the genitourinary tract $(28.0 \%)$. Fertility-sparing surgery $(16.0 \%)$ was the most common method of fertility preservation. The 5 -year survival was better in females $(88.4 \%)$ than in males (79.9\%). The percentage of married AYAs increased following cancer treatment. The proportion of unemployment increased following cancer treatment in all age groups and was greatest (12.6\%) in those aged 20-24 years old. Compared with SEER data from the United States, the incidence of carcinoma was high among AYAs, particularly genitourinary tract carcinomas in females, while the incidence of melanoma and skin carcinomas was low. Therefore, AYAs with cancer requires social and economic support.
\end{abstract}

Correspondence to: Professor Yasuo Saijo, Department of Medical Oncology, Niigata University Graduate School of Medical and Dental Sciences, 1-757 Asahimachi-dori Chuoh-ku, Niigata 951-8510, Japan

E-mail: yasosj@med.niigata-u.ac.jp

Key words: adolescents and young adults, surveillance, epidemiology, cancer treatment, cancer survivor, prognosis

\section{Introduction}

Cancers of adolescents and young adults (AYAs) have distinct biological features compared to both pediatric and adult cancers (1). AYAs face many life events, such as school admission, employment, marriage, childbirth, and raising children. Cancers in AYAs greatly influence their lives after cancer treatment. Therefore, AYAs with cancer need specific support during and after cancer treatment (2). However, cancer in AYAs accounts for only a few cancers and there are various types (3). Consequently, insufficient attention has been paid to cancers in AYAs. Unmet service needs are present in cancers in AYAs, particularly financial, mental health, and support group services (4).

There is no universal definition of AYAs. The National Cancer Institute Surveillance, Epidemiology, and End Results (SEER) program in the United States (3) and other countries (5) initially defined AYAs as those aged between 15 and 29 years old. Recently, however, the program defined widened that range to 15-39 years (6).

In Japan, two reports of cancers in AYAs, defined as from 15 to 39 years old, were published using data from the Monitoring Cancer Incidence in Japan Project for 2009-2011 (7) and 2011-2014 (8). No detailed studies have described the epidemiology, treatment outcomes, and social status of cancers in AYAs in Japan.

The distribution of cancer types in adults that are 30-39 years old is similar to that in those 40 years and older (7-9), and life events such as schooling, employment, and marriage are mainly experienced at 15-29 years of age. Therefore, we defined AYAs as being from 15-29 years old and analyzed the incidence, cancer types, treatment methods, and outcomes of cancer in this group. We also analyzed the family and social status of AYA patients in our institution.

\section{Materials and methods}

Definition of AYAs and cancer classification. We defined AYAs as being 15-29 years old and categorized AYAs according to sex by age groups in 5-year increments (15-19, 20-24, and 25-29 years). Cancer types were classified according to the SEER AYA Site Recode Classification/WHO 2008 Definition (10). We included cases of carcinoma in situ and 
benign tumors in the central nervous system and intracranial neoplasms.

Patients and data collection. This study was approved by the Ethics Review Committee of the School of Medicine of Niigata University (receipt no. 2611). In this retrospective study, we collected data from a hospital-based cancer registry and from electronic medical charts at Niigata University Medical and Dental Hospital from 2007 to 2015.

We analyzed the types of cancer, treatment methods and outcomes, fertility preservation, marital status, whether the patient had children, school admission, and employment status. The treatment methods were classified as surgery, radiation, chemotherapy, endocrine treatment, other treatment, and no treatment. Fertility preservation was classified as sperm banking, fertility-sparing surgery, chemotherapy withdrawal, egg freezing, others, and unknown. Marital status was classified as married, not married, divorced, widowed, and unknown. Marital status, parenting status, and employment were surveyed at the date of diagnosis and last date confirmed. Employment was classified as full-time work, full-time school, part-time work, part-time school, housewife, unemployed, and unknown.

Statistical analyses. Survival curves were drawn using the Kaplan-Meier method. The log-rank test was used to compare survival in each group. Fisher's exact test was used to compare the two groups. For multiple comparisons, the Bonferroni correction was used. $\mathrm{P}<0.05$ was considered to be significant in two groups comparison, $\mathrm{P}<0.017$ in three group comparisons (e.g., age group), $\mathrm{P}<0.0033$ in six group comparisons (e.g., cancer types). All calculations were performed using SPSS Statistics, version 22.0 software (IBM Corp., Armonk, NY, USA).

\section{Results}

Types of cancer and distribution. We identified 399 cancer cases in AYAs (2.1\%) from the 18,663 cases in the hospital-based cancer registry from 2007 to 2015 (Fig. 1A). Of these, patients were excluded if non-cancer was the final diagnosis after surgery or pathological analyses $(n=32$; e.g., severe dysplasia in the uterine cervix), they were not Japanese $(n=2)$, or they were younger than 15 years old at the date of diagnosis $(n=3)$. Ultimately, we identified $362(1.9 \%)$ cancer cases in AYAs (Fig. 1B). Table I shows the age- and sex-specific distributions according to the SEER AYA Site Recode Classification. There were more cases of females (243 cases) than males (119 cases) (Fig. 2).

Fig. 2 shows the distribution of cancer types in AYAs by sex. In males, carcinomas $(29.4 \%)$ were the most common type, followed by germ cell and trophoblastic neoplasms $(15.1 \%)$, leukemias (11.8\%), and CNS and other intracranial and intraspinal neoplasms (all behaviors) (11.8\%) (Fig. 2A). In females, carcinomas $(58.0 \%)$ were the most common, followed by CNS and other intracranial and intraspinal neoplasms (all behaviors) (14.0\%) and soft tissue sarcomas (6.2\%) (Fig. 2B). The carcinomas were subclassified in this analysis. In males, carcinoma of other and ill-defined sites $(11.8 \%)$ were the most common, followed by carcinoma of gastrointestinal tract $(10.1 \%)$ and other carcinoma of head and neck (4.2\%) (Fig. 2A). In females, carcinoma of genitourinary tract (28.0\%) was the
$\mathbf{A}$

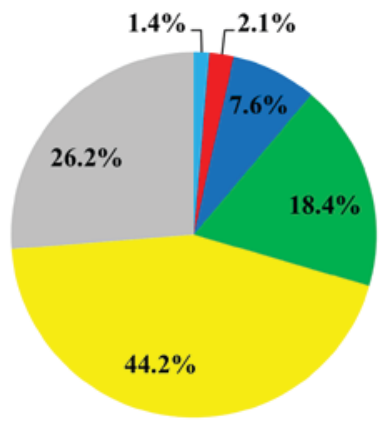

$\mathrm{n}=18,663$

Age (years)

0-14

- 15-29

- 30-44

- 45-59

60-74

$=75$ -

B Hospital-based cancer registry from 2007-2015 $(n=18,663)$

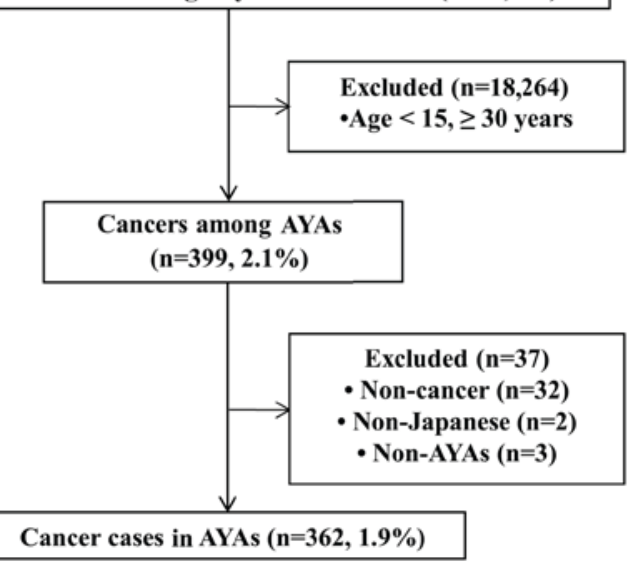

Figure 1. Proportion of cancers among AYAs: Study design and flow diagram. (A) Percentage of cancer cases in each age group. (B) Process used to identify cancer cases in AYAs from the cancer registry. Cancer cases included benign tumors in the central nervous system, intracranial neoplasms, and in situ cancers of any organ. AYAs, adolescents and young adults.

most common, followed by carcinoma of other and ill-defined sites (16.5\%) and thyroid carcinoma (5.3\%) (Fig. 2B). Most of the genitourinary tract cancer was cervical cancer $(n=61$, $25.1 \%$ ). The proportion of carcinomas was significantly higher in females than in males (carcinomas vs. all other types, $\mathrm{P}<0.001$ ), but females had a lower proportion of germ cell and trophoblastic neoplasms and leukemias than did males (germ cell and trophoblastic neoplasms vs. all other types, leukemias vs. all other types, $\mathrm{P}<0.05)$.

Fig. 3 shows the distribution of cancer types in each age group. The number of cases increased with age group with 79 $(21.8 \%), 99(27.3 \%)$, and $184(50.8 \%)$ in the 15-19, 20-24, and 25-29 years groups, respectively. Carcinomas were the most common in all age groups, and the percentage of carcinomas significantly increased with age group (19.0, 45.5, and 63.0\%, respectively; carcinomas vs. all other types, $\mathrm{P}<0.017)$. Three types of cancer decreased with age: germ cell and trophoblastic neoplasms (17.7, 8.1 and 2.7\%, respectively), osseous and chondromatous neoplasms (15.2, 4.0 and 1.6\%, respectively), and soft tissue sarcomas $(12.7,7.1$ and $6.0 \%$, respectively).

Treatments and outcomes. Of the 362 cases, we excluded 12 cases that were admitted to the hospital but not treated because of a second opinion or referral to other hospitals from the analyses of treatments, outcomes, and family/social status.

Surgery $(n=228)$ was the most common treatment method, followed by chemotherapy $(n=136)$, radiation $(n=90)$, endocrine treatment $(n=51)$, no treatment $(n=17)$, and other 
Table I. Cancer classification (age and sex specific distribution).

\begin{tabular}{|c|c|c|c|c|c|c|}
\hline Site group & $\begin{array}{l}\text { Total, } \\
\mathrm{n}(\%)\end{array}$ & $\begin{array}{l}\text { Male, } \\
\mathrm{n}(\%)\end{array}$ & $\begin{array}{l}\text { Female, } \\
\mathrm{n}(\%)\end{array}$ & $\begin{array}{l}\text { Age group, } \\
15-19, \mathrm{n}(\%)\end{array}$ & $\begin{array}{l}\text { Age group, } \\
20-24, \mathrm{n}(\%)\end{array}$ & $\begin{array}{l}\text { Age group } \\
25-29, \mathrm{n}(\%)\end{array}$ \\
\hline Leukemias & $25(6.9)$ & $14(3.9)$ & $11(3.0)$ & $8(2.2)$ & $9(2.5)$ & $8(2.2)$ \\
\hline Acute lymphoid leukemia & $7(1.9)$ & $4(1.1)$ & $3(0.8)$ & $3(0.8)$ & $3(0.8)$ & $1(0.3)$ \\
\hline Acute myeloid leukemia & $15(4.1)$ & $7(1.9)$ & $8(2.2)$ & $4(1.1)$ & $5(1.4)$ & $6(1.7)$ \\
\hline Chronic myeloid leukemia & $3(0.8)$ & $3(0.8)$ & 0 & $1(0.3)$ & $1(0.3)$ & $1(0.3)$ \\
\hline Other and unspecified leukemia & 0 & 0 & 0 & 0 & 0 & 0 \\
\hline Lymphomas & $19(5.2)$ & $8(2.2)$ & $11(3.0)$ & $6(1.7)$ & $5(1.4)$ & $8(2.2)$ \\
\hline Non-Hodgkin lymphoma & $15(4.1)$ & $7(1.9)$ & $8(2.2)$ & $4(1.1)$ & $4(1.1)$ & $7(1.9)$ \\
\hline Hodgkin lymphoma & $4(1.1)$ & $1(0.3)$ & $3(0.8)$ & $2(0.6)$ & $1(0.3)$ & $1(0.3)$ \\
\hline $\begin{array}{l}\text { CNS and other intracranial and intraspinal } \\
\text { neoplasms (all behaviors) }\end{array}$ & $48(13.3)$ & $14(3.9)$ & $34(9.4)$ & $10(2.8)$ & $18(5.0)$ & $20(5.5)$ \\
\hline Astrocytoma & $11(3.0)$ & $2(0.6)$ & $9(2.5)$ & $1(0.3)$ & $3(0.8)$ & $7(1.9)$ \\
\hline Specified low-grade astrocytic tumors & $3(0.8)$ & 0 & $3(0.8)$ & 0 & $1(0.3)$ & $2(0.6)$ \\
\hline $\begin{array}{l}\text { Astrocytoma, NOS Glioblastoma and } \\
\text { anaplastic astrocytoma }\end{array}$ & $4(1.1)$ & $2(0.6)$ & $2(0.6)$ & 0 & $1(0.3)$ & $3(0.8)$ \\
\hline Astrocytoma, NOS & $4(1.1)$ & 0 & $4(1.1)$ & $1(0.3)$ & $1(0.3)$ & $2(0.6)$ \\
\hline Other glioma & $10(2.8)$ & $3(0.8)$ & $7(1.9)$ & 0 & $3(0.8)$ & $7(1.9)$ \\
\hline Ependymoma & $4(1.1)$ & $1(0.3)$ & $3(0.8)$ & $2(0.6)$ & $1(0.3)$ & $1(0.3)$ \\
\hline Medulloblastoma and other PNET & $2(0.6)$ & $1(0.3)$ & $1(0.3)$ & 0 & $1(0.3)$ & $1(0.3)$ \\
\hline Medulloblastoma & $2(0.6)$ & $1(0.3)$ & $1(0.3)$ & 0 & $1(0.3)$ & $1(0.3)$ \\
\hline Supratentorial PNET & 0 & 0 & 0 & 0 & 0 & 0 \\
\hline $\begin{array}{l}\text { Other specified intracranial and intraspinal } \\
\text { neoplasms }\end{array}$ & $14(3.9)$ & $3(0.8)$ & $11(3.0)$ & $3(0.8)$ & $7(1.9)$ & $4(1.1)$ \\
\hline $\begin{array}{l}\text { Unspecified intracranial and intraspinal } \\
\text { neoplasms }\end{array}$ & $7(1.9)$ & $4(1.1)$ & $3(0.8)$ & $4(1.1)$ & $3(0.8)$ & 0 \\
\hline $\begin{array}{l}\text { Unspecified malignant intracranial and } \\
\text { intraspinal neoplasms }\end{array}$ & $4(1.1)$ & $3(0.8)$ & $1(0.3)$ & $3(0.8)$ & $1(0.3)$ & 0 \\
\hline $\begin{array}{l}\text { Unspecified ben/border intracranial and } \\
\text { intraspinal neoplasms }\end{array}$ & $3(0.8)$ & $1(0.3)$ & $2(0.6)$ & $1(0.3)$ & $2(0.6)$ & 0 \\
\hline Osseous and chondromatous neoplasms & $19(5.2)$ & $8(2.2)$ & $11(3.0)$ & $12(3.3)$ & $4(1.1)$ & $3(0.8)$ \\
\hline Osteosarcoma & $12(3.3)$ & $4(1.1)$ & $8(2.2)$ & $9(2.5)$ & $1(0.3)$ & $2(0.6)$ \\
\hline Chondrosarcoma & $2(0.6)$ & 0 & $2(0.6)$ & 0 & $1(0.3)$ & $1(0.3)$ \\
\hline Ewing tumor & $3(0.8)$ & $2(0.6)$ & $1(0.3)$ & $1(0.3)$ & $2(0.6)$ & 0 \\
\hline Other specified and unspecified bone tumors & $2(0.6)$ & $2(0.6)$ & 0 & $2(0.6)$ & 0 & 0 \\
\hline Soft Tissue Sarcomas & $28(7.7)$ & $13(3.6)$ & $15(4.1)$ & $10(2.8)$ & $7(1.9)$ & $11(3.0)$ \\
\hline Fibromatous neoplasms & $5(1.4)$ & $2(0.6)$ & $3(0.8)$ & $1(0.3)$ & 0 & $4(1.1)$ \\
\hline Rhabdomyosarcoma & $2(0.6)$ & $1(0.3)$ & $1(0.3)$ & $2(0.6)$ & 0 & 0 \\
\hline Other soft tissue sarcoma & $21(5.8)$ & $10(2.8)$ & $11(3.0)$ & $7(1.9)$ & $7(1.9)$ & $7(1.9)$ \\
\hline Specified soft tissue sarcoma & $19(5.2)$ & $8(2.2)$ & $11(3.0)$ & $7(1.9)$ & $6(1.7)$ & $6(1.7)$ \\
\hline Specified (excluding Kaposi sarcoma) & $19(5.2)$ & $8(2.2)$ & $11(3.0)$ & $7(1.9)$ & $6(1.7)$ & $6(1.7)$ \\
\hline Kaposi sarcoma & 0 & 0 & 0 & 0 & 0 & 0 \\
\hline Unspecified soft tissue sarcoma & $2(0.6)$ & $2(0.6)$ & 0 & 0 & $1(0.3)$ & $1(0.3)$ \\
\hline Germ cell and Trophoblastic Neoplasms & $27(7.5)$ & $18(5.0)$ & $9(2.5)$ & $14(3.9)$ & $8(2.2)$ & $5(1.4)$ \\
\hline $\begin{array}{l}\text { Germ cell and trophoblastic neoplasms } \\
\text { of gonads }\end{array}$ & $13(3.6)$ & $7(1.9)$ & $6(1.7)$ & $6(1.7)$ & $4(1.1)$ & $3(0.8)$ \\
\hline $\begin{array}{l}\text { Germ cell and trophoblastic neoplasms } \\
\text { of nongonadal sites }\end{array}$ & $14(3.9)$ & $11(3.0)$ & $3(0.8)$ & $8(2.2)$ & $4(1.1)$ & $2(0.6)$ \\
\hline Intracranial (all behaviors) & $11(3.0)$ & $8(2.2)$ & $3(0.8)$ & $6(1.7)$ & $4(1.1)$ & $1(0.3)$ \\
\hline Other nongonadal & $3(0.8)$ & $3(0.8)$ & 0 & $2(0.6)$ & 0 & $1(0.3)$ \\
\hline Melanoma and Skin Carcinomas & $3(0.8)$ & $3(0.8)$ & 0 & 0 & $1(0.3)$ & $2(0.6)$ \\
\hline Melanoma & $2(0.6)$ & $2(0.6)$ & 0 & 0 & $1(0.3)$ & $1(0.3)$ \\
\hline Skin carcinomas & $1(0.3)$ & $1(0.3)$ & 0 & 0 & 0 & $1(0.3)$ \\
\hline
\end{tabular}


Table I. Continued.

\begin{tabular}{|c|c|c|c|c|c|c|}
\hline Site group & $\begin{array}{l}\text { Total, } \\
\mathrm{n}(\%)\end{array}$ & $\begin{array}{l}\text { Male, } \\
\mathrm{n}(\%)\end{array}$ & $\begin{array}{l}\text { Female, } \\
\mathrm{n}(\%)\end{array}$ & $\begin{array}{l}\text { Age group, } \\
15-19, \mathrm{n}(\%)\end{array}$ & $\begin{array}{l}\text { Age group, } \\
20-24, \mathrm{n}(\%)\end{array}$ & $\begin{array}{l}\text { Age group } \\
25-29, \mathrm{n}(\%)\end{array}$ \\
\hline Carcinomas & $176(48.6)$ & $35(9.7)$ & $141(39.0)$ & $15(4.1)$ & $45(12.4)$ & $116(32.0)$ \\
\hline Thyroid carcinoma & $17(4.7)$ & $4(1.1)$ & $13(3.6)$ & $3(0.8)$ & $6(1.7)$ & $8(2.2)$ \\
\hline Other carcinoma of head and neck & $12(3.3)$ & $5(1.4)$ & $7(1.9)$ & 0 & $7(1.9)$ & $5(1.4)$ \\
\hline Nasopharyngeal carcinoma & $1(0.3)$ & $1(0.3)$ & 0 & 0 & $1(0.3)$ & 0 \\
\hline Other sites in lip, oral cavity and pharynx & $10(2.8)$ & $4(1.1)$ & $6(1.7)$ & 0 & $5(1.4)$ & $5(1.4)$ \\
\hline $\begin{array}{l}\text { Nasal cavity, mid ear, sinuses, larynx, } \\
\text { other ill-defined head/neck }\end{array}$ & $1(0.3)$ & 0 & $1(0.3)$ & 0 & $1(0.3)$ & 0 \\
\hline Carcinoma of trachea, bronchus, and lung & 0 & 0 & 0 & 0 & 0 & 0 \\
\hline Carcinoma of breast & $7(1.9)$ & 0 & $7(1.9)$ & 0 & $1(0.3)$ & $6(1.7)$ \\
\hline Carcinoma of genitourinary tract & $68(18.8)$ & 0 & $68(18.8)$ & $1(0.3)$ & $12(3.3)$ & $55(15.2)$ \\
\hline Carcinoma of kidney & $2(0.6)$ & 0 & $2(0.6)$ & 0 & $1(0.3)$ & $1(0.3)$ \\
\hline Carcinoma of bladder & 0 & 0 & 0 & 0 & 0 & 0 \\
\hline Carcinoma of gonads & $4(1.1)$ & 0 & $4(1.1)$ & 0 & $4(1.1)$ & 0 \\
\hline Carcinoma of cervix and uterus & $62(17.1)$ & 0 & $62(17.1)$ & $1(0.3)$ & $7(1.9)$ & $54(14.9)$ \\
\hline $\begin{array}{l}\text { Carcinoma of other and ill-defined sites, } \\
\text { genitourinary tract }\end{array}$ & 0 & 0 & 0 & 0 & 0 & 0 \\
\hline Carcinoma of gastrointestinal tract & $18(5.0)$ & $12(3.3)$ & $6(1.7)$ & $2(0.6)$ & $6(1.7)$ & $10(2.8)$ \\
\hline Carcinoma of colon and rectum & $7(1.9)$ & $5(1.4)$ & $2(0.6)$ & $1(0.3)$ & $3(0.8)$ & $3(0.8)$ \\
\hline Carcinoma of stomach & $5(1.4)$ & $3(0.8)$ & $2(0.6)$ & 0 & $1(0.3)$ & $4(1.1)$ \\
\hline $\begin{array}{l}\text { Carcinoma of liver and intrahepatic } \\
\text { bile ducts }\end{array}$ & $2(0.6)$ & $2(0.6)$ & 0 & $1(0.3)$ & $1(0.3)$ & 0 \\
\hline Carcinoma of pancreas & $3(0.8)$ & $1(0.3)$ & $2(0.6)$ & 0 & $1(0.3)$ & $2(0.6)$ \\
\hline $\begin{array}{l}\text { Carcinoma other and ill-defined sites, } \\
\text { gastrointestinal tract }\end{array}$ & $1(0.3)$ & $1(0.3)$ & 0 & 0 & 0 & $1(0.3)$ \\
\hline Carcinoma of other and ill-defined sites & $54(14.9)$ & $14(3.9)$ & $40(11.0)$ & $9(2.5)$ & $13(3.6)$ & $32(8.8)$ \\
\hline Adrenocortical carcinoma & $1(0.3)$ & 0 & $1(0.3)$ & 0 & 0 & $1(0.3)$ \\
\hline $\begin{array}{l}\text { Carcinoma of other and ill-defined } \\
\text { sites, NOS }\end{array}$ & $53(14.6)$ & $14(3.9)$ & $39(10.8)$ & $9(2.5)$ & $13(3.6)$ & $31(8.6)$ \\
\hline Miscellaneous specified neoplasms, NOS & $12(3.3)$ & $3(0.8)$ & $9(2.5)$ & $2(0.6)$ & $1(0.3)$ & $9(2.5)$ \\
\hline Other pediatric and embryonal tumors, NOS & $3(0.8)$ & $1(0.3)$ & $2(0.6)$ & $1(0.3)$ & 0 & $2(0.6)$ \\
\hline Wilms tumor & 0 & 0 & 0 & 0 & 0 & 0 \\
\hline Neuroblastoma & 0 & 0 & 0 & 0 & 0 & 0 \\
\hline Other pediatric and embryonal tumors, NOS & $3(0.8)$ & $1(0.3)$ & $2(0.6)$ & $1(0.3)$ & 0 & $2(0.6)$ \\
\hline Other specified and embryonal tumors, NOS & $9(2.5)$ & $2(0.6)$ & $7(1.9)$ & $1(0.3)$ & $1(0.3)$ & $7(1.9)$ \\
\hline Paraganglioma and glomus tumors & 0 & 0 & 0 & 0 & 0 & 0 \\
\hline Other specified gonadal tumors & 0 & 0 & 0 & 0 & 0 & 0 \\
\hline $\begin{array}{l}\text { Myeloma, mast cell, miscellaneous } \\
\text { lymphoreticular neoplasms, NOS }\end{array}$ & $2(0.6)$ & 0 & $2(0.6)$ & 0 & 0 & $2(0.6)$ \\
\hline Other specified neoplasms, NOS & $7(1.9)$ & $2(0.6)$ & $5(1.4)$ & $1(0.3)$ & $1(0.3)$ & $5(1.4)$ \\
\hline Unspecified Malignant Neoplasms & $1(0.3)$ & 0 & $1(0.3)$ & 0 & 0 & $1(0.3)$ \\
\hline \# Unclassified & $4(1.1)$ & $3(0.8)$ & $1(0.3)$ & $2(0.6)$ & $1(0.3)$ & $1(0.3)$ \\
\hline Total & $362(100)$ & $119(32.9)$ & $243(67.1)$ & $79(21.8)$ & $99(27.3)$ & $184(50.8)$ \\
\hline
\end{tabular}

treatments $(\mathrm{n}=5)$. Radiation included total body irradiation $(n=16)$ for leukemia and lymphoma. Other treatments included thermal therapy (1 case), WT1 antigen vaccination (1 case), immunotherapy (1 case), and steroid ointment treatment ( 2 cases). Fig. 4A shows the treatments involving combined modes. Surgery + chemotherapy $(n=44)$ was the most common combined modality, followed by chemotherapy + radiation $(n=28)$, surgery + chemotherapy + radiation $(n=28)$, surgery + radiation $(n=15)$, surgery + endocrine treatment $(n=13)$, and others $(n=12)$.

Of the patients, $20.3 \%$ underwent fertility preservation (Fig. 4B). More females underwent fertility preservation 


\section{A Males $\mathrm{n}=119($ carcinomas $\mathrm{n}=35)$}

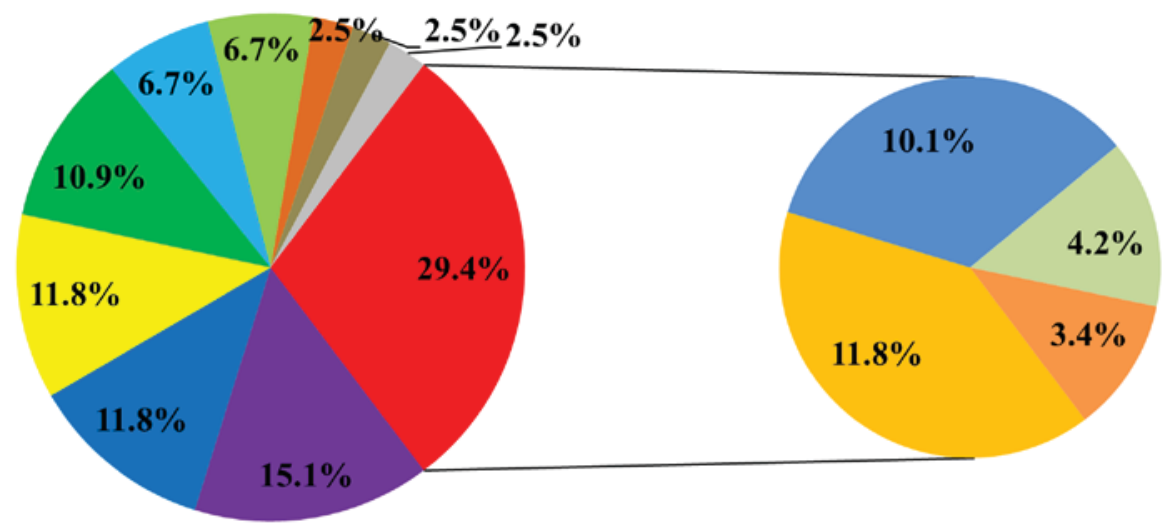

B Females $n=243($ carcinomas $n=141)$

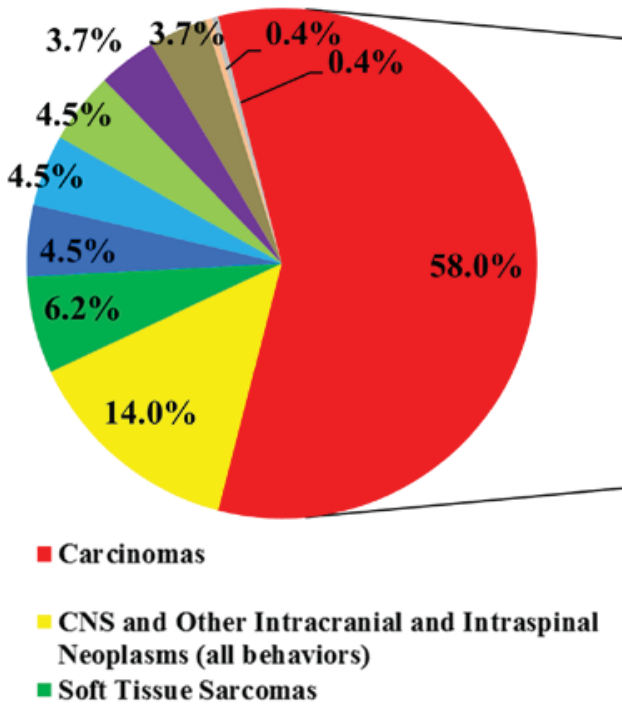

n Miscellaneous specified neoplasms, NOS

- Leukemias

- Lymphomas

n Germ cell and Trophoblastic Neoplasms

= Osseous \& Chondromatous Neoplasms

= Melanoma and Skin Carcinomas

Unspecified Malignant Neoplasms

Unclassified

Figure 2. Distribution of cancer types in adolescents and young adults by sex. (A) Males ( $n=119)$, carcinomas ( $n=35)$. (B) Females ( $n=243)$, carcinomas ( $n=141)$.

(females $24.7 \%$, males 9.2\%). Fertility-sparing surgery (16.0\%) was the most common method of fertility preservation, mainly for cervical cancers, followed by sperm banking (3.1\%).

Fig. 5 shows the treatment outcomes of the cancers in AYAs. The 5-year survival rate was $85.6 \%$ in all AYA cases $(n=350)$ and was better in females $(88.4 \%)$ than in males (79.9\%). Overall survival curves were drawn for several factors, including sex, age group, and cancer types (Fig. 5). The treatment outcomes were significantly $(\mathrm{P}<0.05)$ better in females (Fig. 5A). Comparing the age groups, the 15-19 years group had a significantly $(\mathrm{P}<0.017)$ worse outcome than the
25-29 years group (Fig. 5B). Cancer types were categorized as i) leukemias/lymphomas; ii) CNS and other intracranial and intraspinal neoplasms (all behaviors); iii) osseous and chondromatous neoplasms/soft tissue sarcomas; iv) germ cell and trophoblastic neoplasms; v) melanoma and skin carcinomas/miscellaneous specified neoplasms, NOS/unspecified malignant neoplasms/unclassified; and vi) carcinomas. Comparing cancer types, the treatment outcomes were not significantly different among the six groups (Fig. 5C). Carcinomas $(n=168)$ were further classified and analyzed separately, as shown in Fig. 5D. No patients died of thyroid 


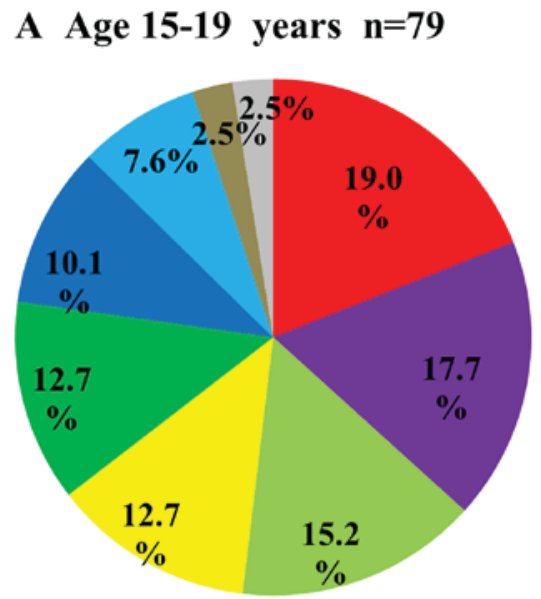

\section{Age 25-29 years $n=184$}

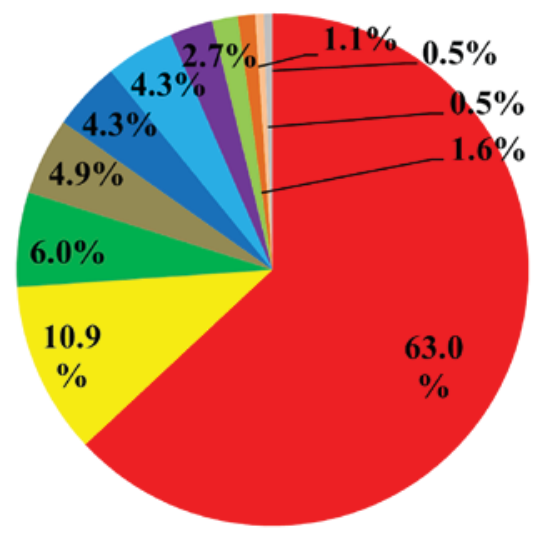

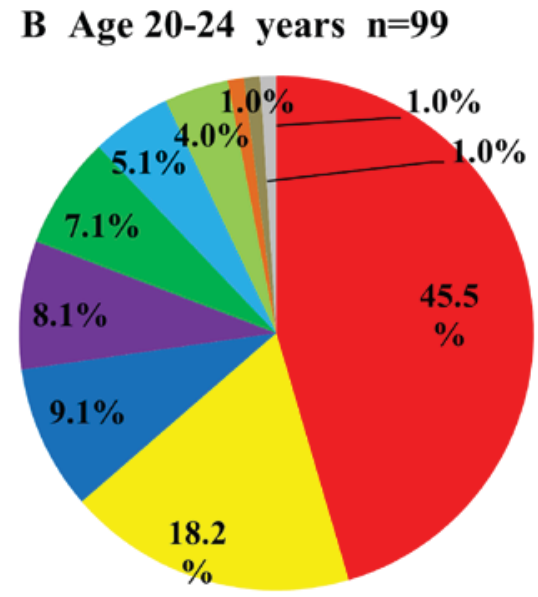

- Carcinomas

- CNS and Other Intracranial and Intraspinal

Neoplasms (all behaviors)

- Soft Tissue Sarcomas

Miscellan eous specified neoplasms, NOS

- Leukemias

- Lymphomas

ص Germ cell and Trophoblastic Neoplasms

= Osseous \& Chondromatous Neoplasms

- Melanoma and Skin Carcinomas

Unspecified Malignant Neoplasms

= Unclassified

Figure 3. Distribution of cancer types in adolescents and young adults by age group. (A) Age 15-19 years (n=79). (B) Age 20-24 years (n=99). (C) Age $25-29$ years $(n=184)$.

carcinoma or other carcinoma of head and neck. Carcinoma of gastrointestinal tract had a significantly worse outcome than that of carcinoma of other and ill-defined sites $(\mathrm{P}<0.0033$, Fig. 5D).

Family and social status. At the date last confirmed, the proportion of married AYAs significantly increased with age group (married vs. all other marital statuses, 15-19, 20-24, 25-29 years old, $\mathrm{P}<0.017)$. The proportion of married cases at a diagnosis of cancer was $0,9.5$, and $29.9 \%$ in the $15-19$, 20-24, and 25-29 years groups, respectively (Fig. 6A); at the date last confirmed, these values were 2.6, 21.1, and 44.1\%. The percentage of patients raising children increased with age group and was $0 / 1.3 \%$ (at diagnosis/date last confirmed), 7.4/15.8, and $19.8 \% / 33.9 \%$, respectively (Fig. 6B). When marriage status and parenting status were compared by sex, the proportions of patients who were married and raising children were higher among females than males both at diagnosis and at date last confirmed ( $\mathrm{P}<0.01$; Fig. $6 \mathrm{~A}$ and $\mathrm{B})$. The proportion of patients who were married or raising children was higher at date last confirmed than at diagnosis among females $(\mathrm{P}<0.001)$, but not among males (Fig. 6A and B). Patients with carcinoma of genitourinary tract were more likely to be married $(60.0 \%)$ or raising children $(47.7 \%)$ compared with the other types of cancer (21.4,
15.8\%; $\mathrm{P}<0.001)$. Patients with fertility preservation were also more likely to be married $(50.7 \%)$ or raising children $(39.4 \%)$ compared with the other groups (no fertility preservation and unknown status, 22.9 and $17.2 \%$, respectively; $\mathrm{P}<0.001$ ).

The proportion of unemployed patients significantly increased after cancer treatment in the 15-19 and 20-24 year age groups (unemployed vs. all other employment statuses, $\mathrm{P}<0.05$ ), but not in the 25-29 year age group, and was greatest in the 20-24 year age group at the date last confirmed (at diagnosis/date last confirmed: 1.3/9.0, 3.2/12.6, and 4.5\%/7.9\% in the 15-19, 20-24, and 25-29 year age groups; Fig. 6C). At the date last confirmed, the proportion of unemployed patients was not significantly different among the three age groups (unemployed vs. all other employment statuses).

\section{Discussion}

This study analyzed 362 AYAs (15 to 29 years old) with cancer seen in Niigata University Medical and Dental Hospital between 2007 and 2015. The most common cancers in both males and females were carcinomas. The 5-year survival was $79.9 \%$ in males and $88.4 \%$ in females. More than $40 \%$ of the patients in the 25-29 years group were married, at the date last confirmed. 


\section{A Treatments $\mathrm{n}=\mathbf{3 5 0}$}

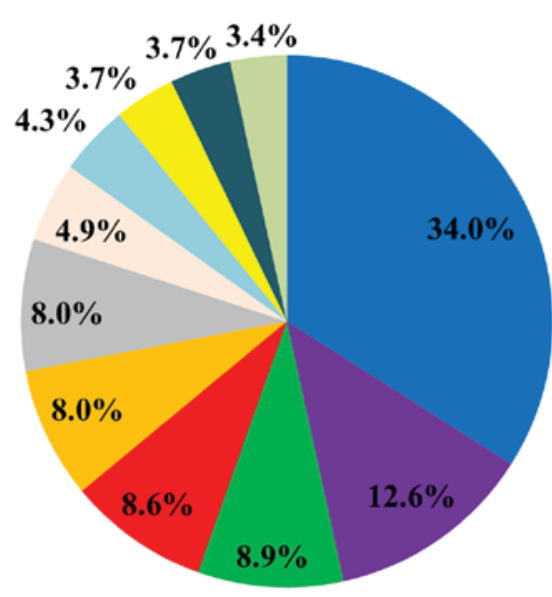

" Surgery only

n Surgery + Chemotherapy

Endocrine treatment only

n Chemotherapy only

"Chemotherapy + Radiation

$=$ Surgery + Chemotherapy + Radiation

No treatment

"Surgery + Radiation

Radiation only

- Surgery + Endocrine treatment

\#thers

\section{B Fertility preservation $n=350$}

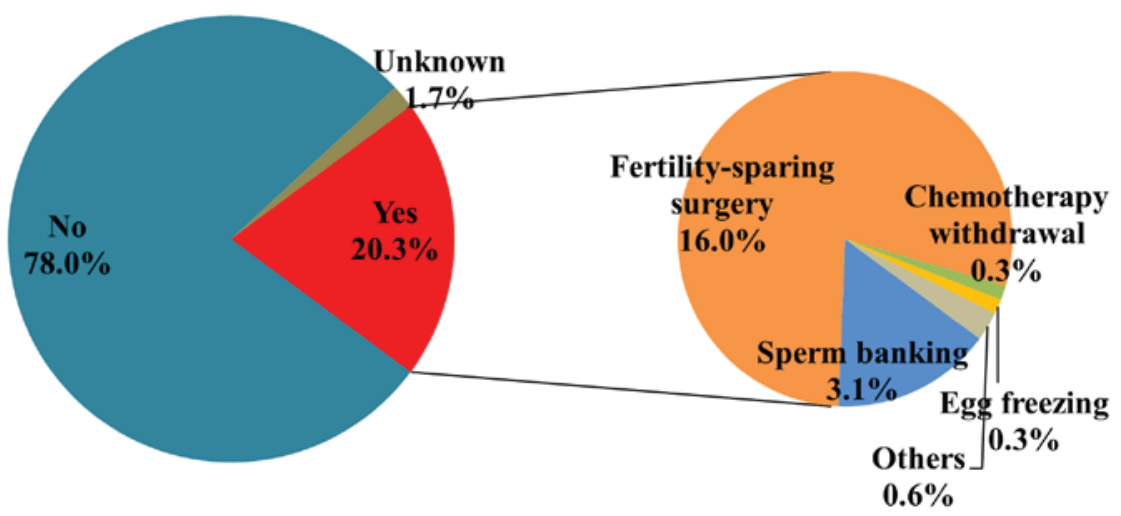

Figure 4. Treatment method and fertility preservation in cancers in adolescents and young adults. (A) Treatments (n=350). (B) Fertility preservation ( $\mathrm{n}=350)$.

We compared our data with relatively old SEER data from 1975 to 2000 (3), due to the recent widening of the definition of AYA by SEER. In the older SEER data, $2.0 \%$ of AYAs (15-29 years) had cancers, compared to 2.3\% in Korea (1999 to 2010) (11). At our institution, $1.9 \%$ of AYAs (15-29 years) had cancers. Overall, the incidence of cancers in AYAs was similar in Japan, the USA, and Korea.

At our institution, the most common cancers were carcinomas, particularly in females, followed by germ cell and trophoblastic neoplasms in males and CNS and other intracranial and intraspinal neoplasms in females. In comparison, in a national incidence study in Japan (7), leukemia and germ cell and other gonadal tumors were most common in the 15-19 and 20-29 years groups, respectively, although the disease classification differed slightly. This difference could be specific to our institution. In Korea, the most common cancer was carcinoma, followed by leukemias. In the USA, lymphoma was most common, followed by invasive skin cancer.

At our institution, carcinoma of genitourinary tract was most common and accounted for $28.0 \%$ of the cancers in female AYAs. Most such cancers were cervical cancer, including carcinoma in situ. Cervical cancer is caused by human papilloma virus (HPV) infection (12), and is preventable by vaccination (13-15). However, the Japanese Ministry of Health, Labor and Welfare withdrew its recommendation for vaccination against HPV because of controversy regarding its adverse effects $(16,17)$. Consequently, the high incidence of cervical cancer will continue. Screening for cervical cancer in women over 20 years old should be continued in Japan.

Surgery was the most common treatment modality because of the high percentage of carcinomas in AYAs. While 20.3\% of the patients underwent fertility preservation, mainly due to fertility-sparing surgery for cervical cancer in females and sperm banking in males, $80 \%$ of the patients did not receive any fertility preservation. Sperm banking was performed only in $9.2 \%$ of males, which was markedly lower than the $17.8 \%$ in male AYAs reported in the USA (18). Egg freezing was performed in one case only. Sperm banking and egg freezing should be performed widely in AYA cancer patients in Japan. The National Comprehensive Cancer Network (19) and American Society of Clinical Oncology (20) guidelines recommend discussing the possibility of infertility and use of fertility preservation before initiating treatment.

The 5-year survival was better in females (88.4\%) than in males (79.9\%), and was better than those for cancer at all ages (males 59.1\%, females 66.0\%) (9). The treatment outcome was worse in the 15-19 years age group, probably due to the high percentage of soft tissue sarcoma, osseous and trophoblastic 
A Sex $\mathbf{n}=\mathbf{3 5 0}$

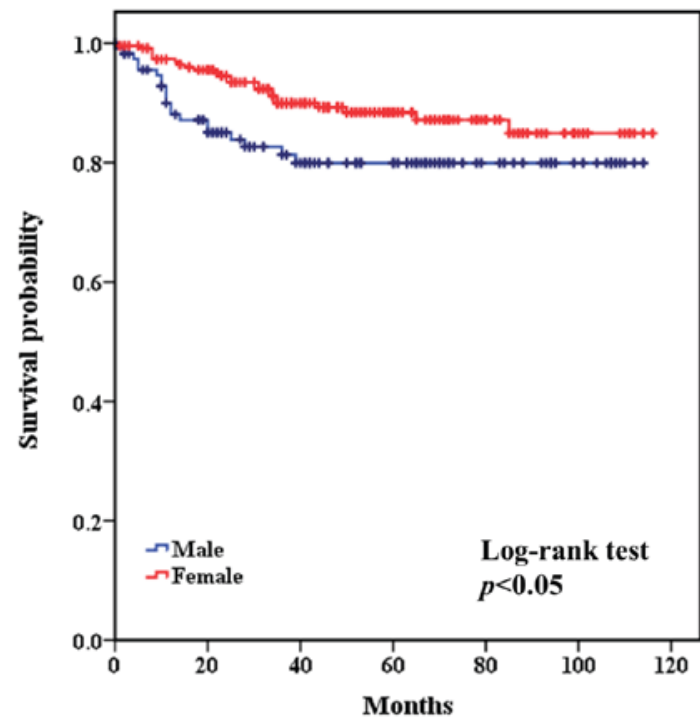

C Cancer types $n=350$

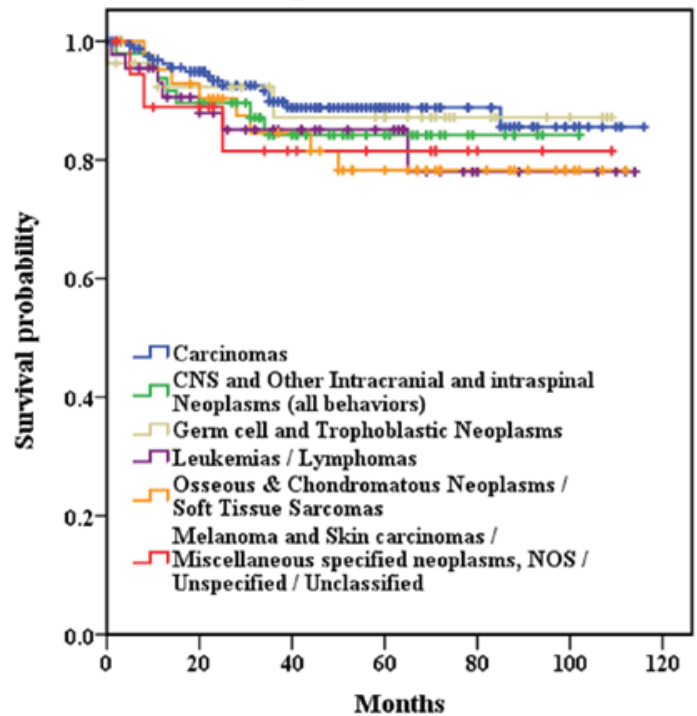

B Age group $\mathbf{n}=\mathbf{3 5 0}$

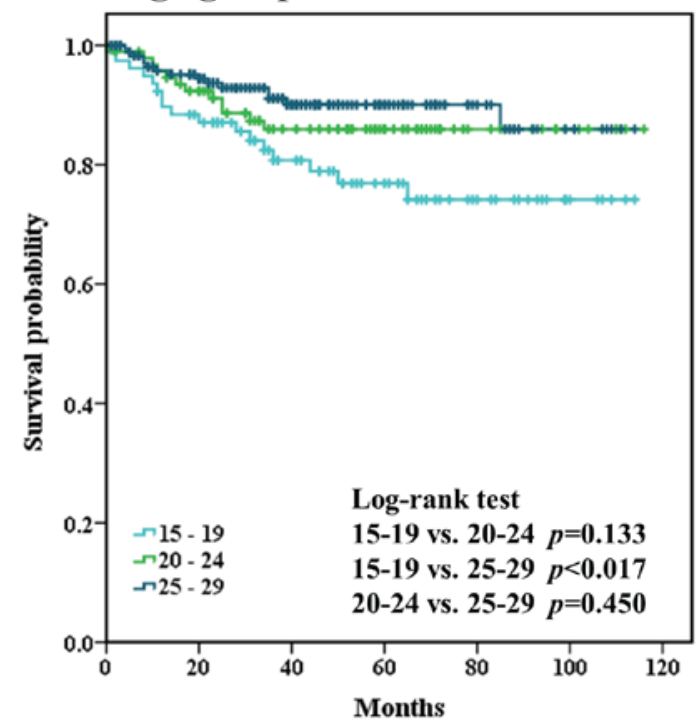

D Carcinomas $n=168$

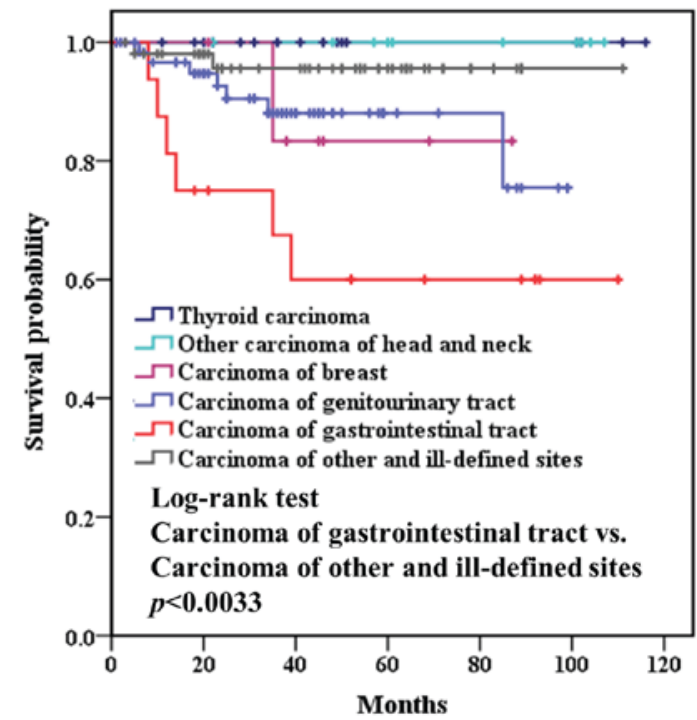

Figure 5. Outcome of cancer treatments in adolescents and young adults. Overall survival curves were drawn based on several factors. (A) Sex ( $=350)$, $P<0.05$. (B) Age group ( $\mathrm{n}=350$ ), $15-19$ vs. 20-24; $\mathrm{P}=0.133 ; 15-19$ vs. $25-29, \mathrm{P}<0.017 ; 20-24$ vs. 25-29, $\mathrm{P}=0.450$. (C) Cancer type ( $\mathrm{n}=350)$. (D) Carcinomas ( $=168$ ), carcinoma of gastrointestinal tract vs. carcinoma of other and ill-defined sites, $\mathrm{P}<0.0033$.

neoplasms, and leukemia/lymphoma. The 10-year relative survival in AYAs (15-29 years) (males 66.0\%, females 75.3\%) is worse than those in children (0-14 years) (males $73.2 \%$, females $79.3 \%$ ) in Japan (21). The treatment outcomes for cancer in AYAs is worse than that in pediatric patients with leukemia. ${ }^{21}$ However, acute lymphoblastic leukemia in AYAs has an improved prognosis with intensive chemotherapy (22). The chemotherapy regimens used for pediatric cancer should be applied to these cancers in AYAs because such regimens have better prognoses than adult regimens for cancer in AYAs (23). Among the cancer types, carcinomas and germ cell and trophoblastic neoplasms had better prognoses. None of the patients with thyroid carcinoma or other carcinoma of head and neck died. In many countries, the incidence of thyroid cancer has increased (24-26). Although the reason for the increased incidence of thyroid cancer in AYAs is unclear, improved screening technology, including ultrasound, which can detect early thyroid cancer, might have led to the increased detection of thyroid cancer (27). In AYAs, we might over-diagnose thyroid cancer, which is not malignant and not lethal (28). Carcinoma of gastrointestinal tract and breast cancers had poorer prognoses in AYAs than in older patients, which suggests that these carcinomas have different biological features in AYAs and need different approaches for detection and treatment (29).

In terms of marital status, the proportion of married patients at diagnosis increased with age group and was $0,9.5$, and $29.9 \%$, respectively. These proportions are similar to those in healthy individuals at similar ages $(0.4,6.6$, and $31.5 \%)$ based on the 2015 welfare survey in Japan (30). In addition, many patients married after their diagnoses.

The percentage with children increased after diagnosis in all three age groups, which suggests that fertility was maintained in many cases. The high proportion of genitourinary tract 
A Marital status $\mathbf{n}=\mathbf{3 5 0}$
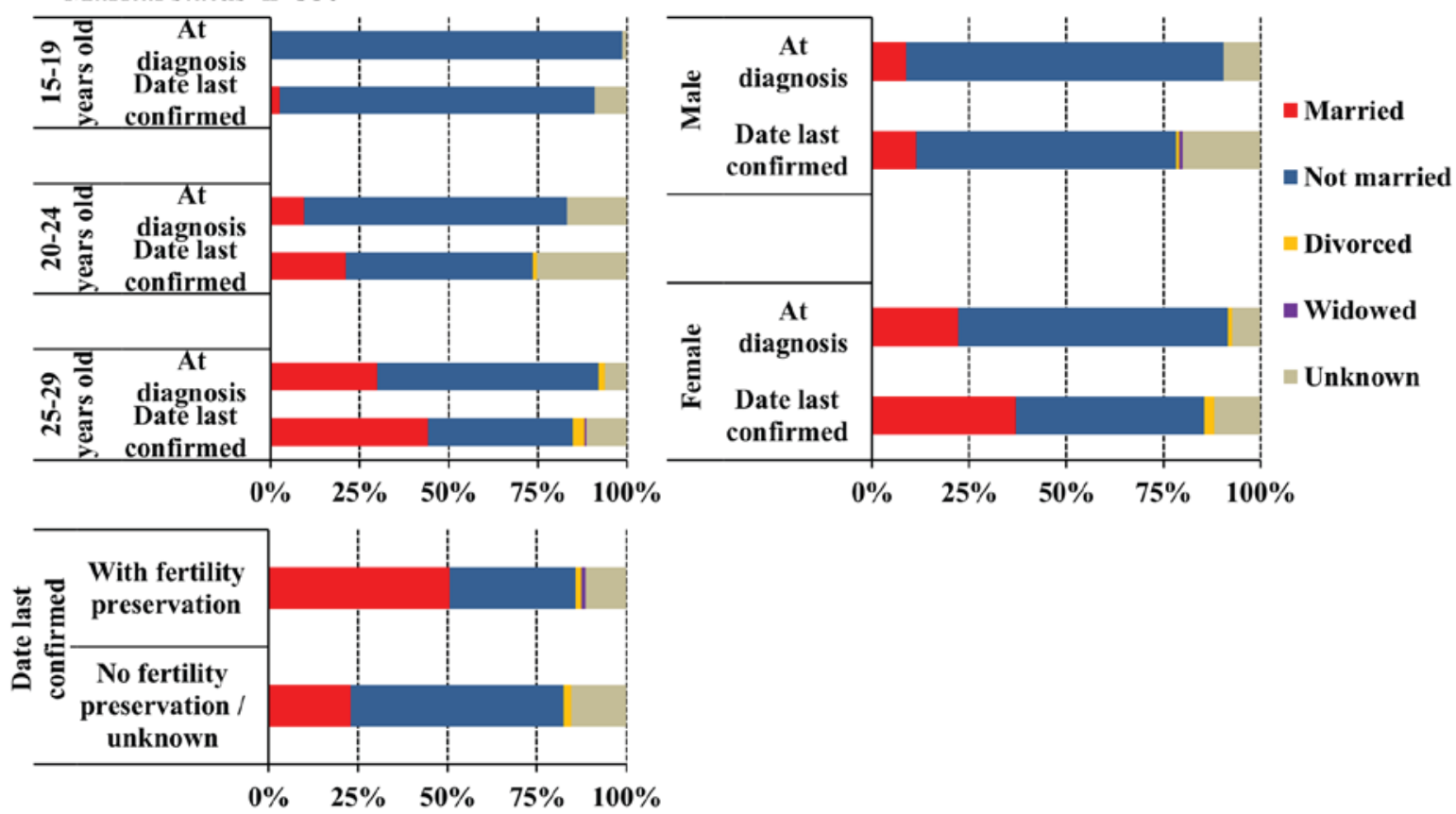

B Raising children $\mathbf{n}=\mathbf{3 5 0}$
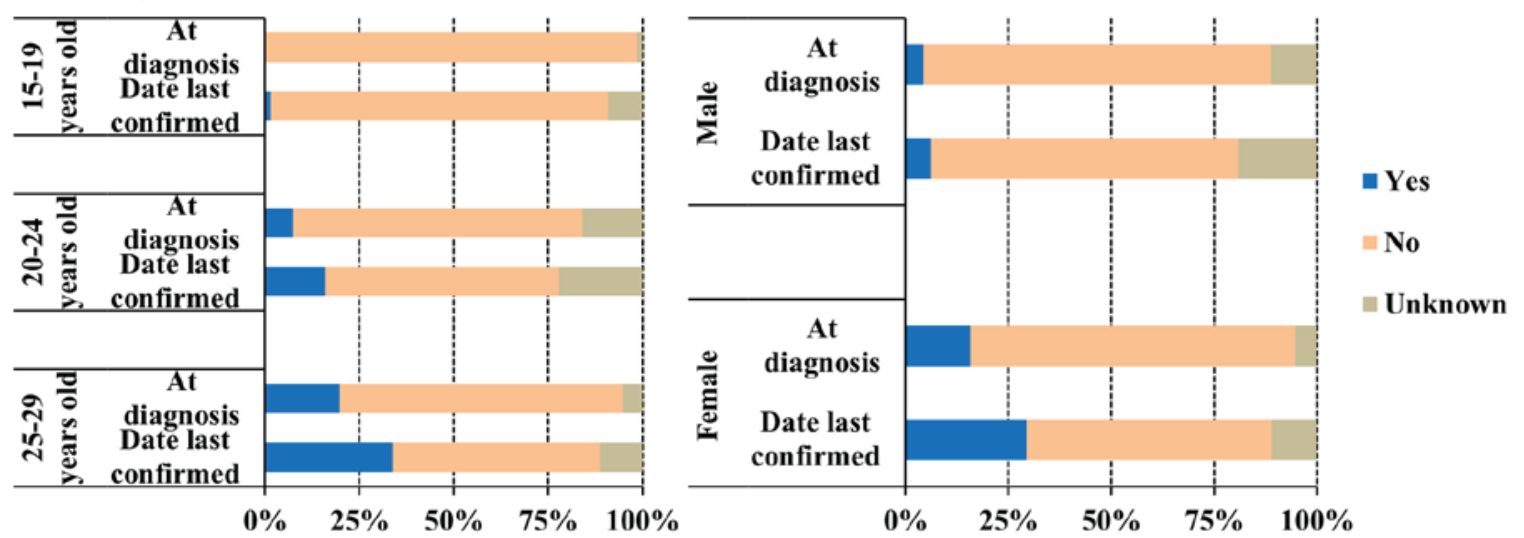

C Employment $n=350$
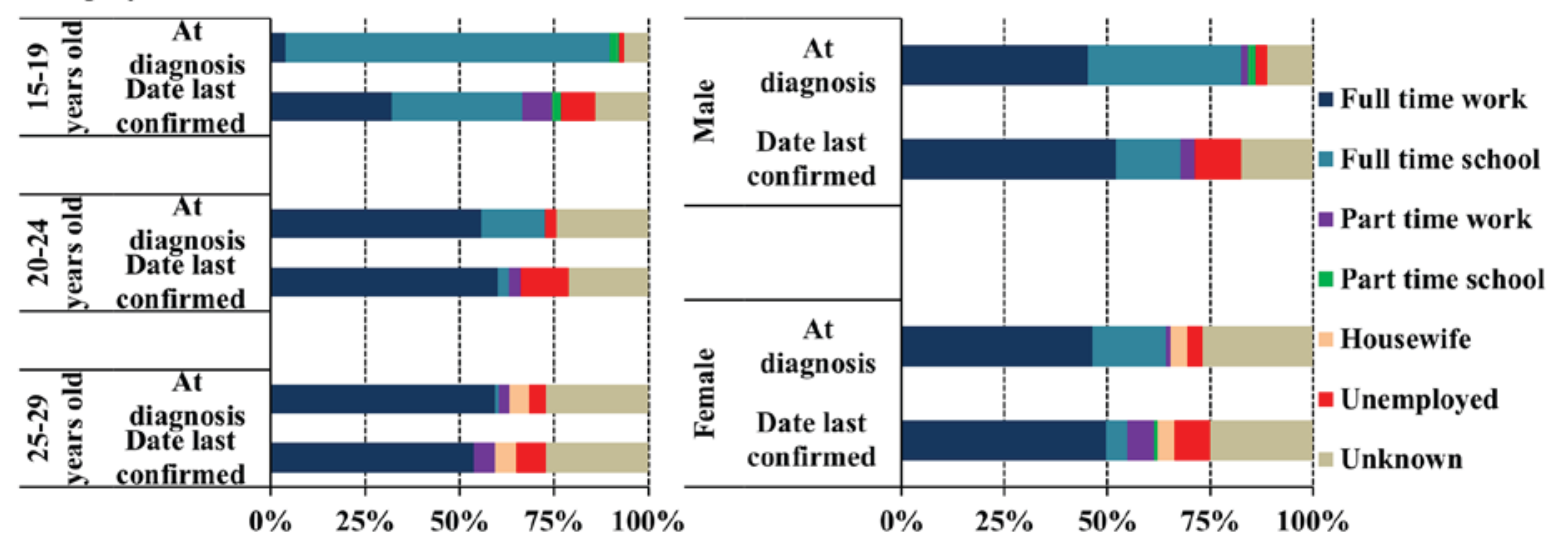

Figure 6. Family and social status of adolescents and young adults by age group and sex. (A) Marital status ( $\mathrm{n}=350)$ : Married at diagnosis (male vs. female), $\mathrm{P}<0.01$; date last confirmed, $\mathrm{P}<0.001 /$ married (at diagnosis vs. date last confirmed): male, $\mathrm{P}=0.33$; female, $\mathrm{P}<0.001$. (B) Raising children ( $\mathrm{n}=350$ ): Yes (male vs female) at diagnosis, $\mathrm{P}<0.001$, date last confirmed, $\mathrm{P}<0.001 /$ yes (at diagnosis vs. date last confirmed): Male, $\mathrm{P}=0.38$; female, $\mathrm{P}<0.001$. (C) Employment $(\mathrm{n}=350)$ : Unemployed (at diagnosis vs. date last confirmed): $15-19$ years, $\mathrm{P}<0.05 ; 20-24$ years, $\mathrm{P}<0.05 ; 25-29$ years, $\mathrm{P}=0.135$.

carcinoma patients who were married and raising children at the date last confirmed could be due to fertility-sparing surgery for cervical cancers. In this context, fertility preservation is important for marriage and childbirth in AYA cancer survivors.
Employment is a very important issue in AYA cancer patients. The proportion employed (full time or part time) at the date last confirmed was $56.0 \%(196 / 350)$ at our institution. This is similar to the results of Tai et al (31), who found that 
49.4\% of AYA cancer survivors were employed for wages. Financial support and job training are definitely needed for AYA cancer survivors.

The cancers in AYAs varied. There was a high incidence of carcinoma, particularly genitourinary tract carcinomas in females, and a low incidence of melanoma and skin carcinomas among AYAs in Japan compared to the SEER data. Fertility-sparing surgery was the most common method of fertility preservation. Social and economic support is need for AYAs with cancer.

\section{Acknowledgements}

Not applicable.

\section{Funding}

No funding was received.

\section{Availability of data and materials}

All data generated or analyzed during this study are included in this published article.

\section{Authors' contributions}

KK drafted the manuscript. KK, YM and QZ contributed to the collection and analysis of the data. MM and YS conceived and designed the study, and edited the manuscript. All authors approved the final manuscript.

\section{Ethics approval and consent to participate}

The present study was approved by the Ethics Review Committee of the School of Medicine of Niigata University (Niigata, Japan; no. 2611).

\section{Patient consent for publication}

Not applicable.

\section{Competing interests}

The authors declare that they have no competing interests.

\section{References}

1. Bleyer A, Barr R, Hayes-Lattin B, Thomas D, Ellis C and Anderson B; Biology and Clinical Trials Subgroups of the US National Cancer Institute Progress Review Group in Adolescent and Young Adult Oncology: The distinctive biology of cancer in adolescents and young adults. Nat Rev Cancer 8: 288-298, 2008.

2. Nass SJ, Beaupin LK, Demark-Wahnefried W, Fasciano K, Ganz PA, Hayes-Lattin B, Hudson MM, Nevidjon B, Oeffinger KC, Rechis R, et al: Identifying and addressing the needs of adolescents and young adults with cancer: Summary of an institute of medicine workshop. Oncologist 20: 186-195, 2015.

3. Bleyer A, Leary MO, Barr R and Ries LA (eds): Cancer epidemiology in older adolescents and young adults 15 to 29 years of age, including SEER incidence and survival: 1975-2000. National Cancer Institute, Bethesda, MD, NIH Pub. No. 06-5767, 2006
4. Smith AW, Parsons HN, Kent EE, Bellizi K, Zebrack BJ, Keel G, Lynch CF, Rubenstein MB and Keegan TH; AYA HOPE Study Collaborative Group: Unmet support service needs and health-related quality of life among adolescents and young adults with cancer: The AYA HOPE study. Front Oncol 3: 75, 2013.

5. Canadian Cancer and Society: Canadian Cancer Statistics 2017. http://www.cancer.ca/statistics/. Accessed March 25, 2018.

6. National Cancer institute: SEER Cancer Statistics Review 1975-2014. https://seer.cancer.gov/csr/1975_2014/results_ merged/sect_32_aya.pdf/. Accessed March 25, 2018.

7. Katanoda K, Shibata A, Matsuda T, Hori M, Nakata K, Narita Y, Ogawa C, Munakata W, Kawai A and Nishimoto H: Childhood, adolescent and young adult cancer incidence in Japan in 2009-2011. Jpn J Clin Oncol 47: 762-771, 2017.

8. Inoue I, Nakamura F, Matsumoto K, Takimoto $T$ and Higashi T: Cancer in adolescents and young adults: National incidence and characteristics in Japan. Cancer Epidemiol 51: 74-80, 2017.

9. Cancer statistics in Japan: Center for Cancer Registries, Center for Cancer Control and Information Services, National Cancer Center, Japan. https://ganjoho.jp/reg_stat/statistics/stat/summary. html. Accessed March 25, 2018.

10. National Cancer Institute: AYA Site recode/WHO 2008 Definition. https://seer.cancer.gov/ayarecode/aya-who2008.html. Accessed March 25. 2018.

11. Moon EK, Park HJ, Oh CM, Jung KW, Shin HY, Park BK and Won YJ: Cancer incidence and survival among adolescents and young adults in Korea. PLoS One 9: e96088, 2014.

12. Schiffman M, Castle PE, Jeronimo J, Rodriguez AC and Wacholder S: Human papillomavirus and cervical cancer. Lancet 370: 890-907, 2007.

13. FUTURE II Study Group: Quadrivalent vaccine against human papillomavirus to prevent high-grade cervical lesions. N Engl J Med 356: 1915-1927, 2007.

14. Harper DM, Franco EL, Wheeler CM, Moscicki AB, Romanowski B, Roteli-Martins CM, Jenkins D, Schuind A, Costa Clemens SA and Dubin G; HPV Vaccine Study group: Sustained efficacy up to 4.5 years of a bivalent L1 virus-like particle vaccine against human papillomavirus types 16 and 18: Follow-up from a randomised control trial. Lancet 367: 1247-1255, 2006.

15. Paavonen J, Jenkins D, Bosch FX, Naud P, Salmerón J, Wheeler CM, Chow SN, Apter DL, Kitchener HC, Castellsague X, et al: Efficacy of a prophylactic adjuvanted bivalent L1 virus-like-particle vaccine against infection with human papillomavirus types 16 and 18 in young women: An interim analysis of a phase III double-blind, randomised controlled trial. Lancet 369: 2161-2170, 2007.

16. Sauvaget C, Nishino Y, Konno R, Tase T, Morimoto $T$ and Hisamichi S: Challenges in breast and cervical cancer control in Japan. Lancet 17: e305-e312, 2016.

17. Japanese Ministry of Health, Labor and Welfare: HPV, Hib, pediatric pneumococcal vaccines. http://www.mhlw. go.jp/bunya/kenkou/kekkaku-kansenshou28/. Accessed March 25, 2018.

18. Neal MS, Nagel K, Duckworth J, Bissessar H, Fischer MA, Portwine C, Tozer R and Barr RD: Effectiveness of sperm banking in adolescents and young adults with cancer: A regional experience. Cancer 110: 1125-1129, 2007.

19. Coccia PF, Pappo AS, Beaupin L, Borges VF, Borinstein SC, Chugh R, Dinner S, Folbrecht J, Frazier AL, Goldsby R, et al: Adolescent and young adult oncology, Version 2.2018, NCCN clinical practice guidelines in oncology. J Natl Compr Canc Netw 16: 66-97, 2018.

20. Loren AW, Mangu PB, Beck LN, Brennan L, Magdalinski AJ, Partridge AH, Quinn G, Wallace WH and Oktay K; American Society of Clinical Oncology: Fertility preservation for patients with cancer: American Society of Clinical Oncology clinical practice guideline update. J Clin Oncol 31: 2500-2510, 2013.

21. Ito Y, Miyashiro I, Ito H, Hosono S, Chihara D, Nakata-Yamada K, Nakayama M, Matsuzaka M, Hattori M, Sugiyama H, et al: Long-term survival and conditional survival of cancer patients in Japan using population-based cancer registry data. Cancer Sci 105: 1480-1486, 2014.

22. Pui CH, Pei D, Campana D, Bowman WP, Sandlund JT, Kaste SC, Ribeiro RC, Rubnitz JE, Coustan-Smith E, Jeha S, et al: Improved prognosis for older adolescents with acute lymphoblastic leukemia. J Clin Oncol 29: 386-391, 2011. 
23. Hayakawa F, Sakura T, Yujiri T, Kondo E, Fujimaki K, Sasaki O, Miyatake J, Handa H, Ueda Y, Aoyama Y, et al: Markedly improved outcomes and acceptable toxicity in adolescents and young adults with acute lymphoblastic leukemia following treatment with a pediatric protocol: A phase II study by the Japan Adult Leukemia Study Group. Blood Cancer J 4: e252, 2014.

24. Howlader N, Noone AM, Krapcho M, Miller D, Bishop K, Altekruse SF, Kosary CL, Yu M, Ruhl J, Tatalovich Z, et al (eds): SEER Cancer Statistics Review, 1975-2013. National Cancer Institute, Bethesda, MD, based on November 2015 SEER data submission, posted to the SEER website, April 2016. http://seer.cancer.gov/csr/1975_2013. Accessed March 25, 2018.

25. Ahn HS, Kim HJ and Welch HG: Korea's thyroid-cancer 'epidemic': Screening and overdiagnosis. N Engl J Med 371: 1765-1767, 2014.

26. Ahn HS and Welch HG: South Korea's thyroid-cancer 'epidemic': Turning the tide. N Engl J Med 373: 2389-2390, 2015

27. Vaccarella S, Franceschi S, Bray F, Wild CP, Plummer M and Dal Maso L: Worldwide thyroid-cancer epidemic? The increasing impact of overdiagnosis. N Engl J Med 375: 614-617, 2016.
28. Takano T: Natural history of thyroid cancer [Review]. Endocr J 64: 237-244, 2017.

29. Adolescent and Young Adult Oncology Progress Review Group: Closing the Gap: Research and care imperatives for adolescents and young adults with cancer. Report of the Adolescent and Young Adult Oncology Progress Review Group. U.S. Department of Health and Human Services, National Institutes of Health, National Cancer Institutes and the LIVESTRONG Young Adults Alliance. NIH Publication no. 06-6067, 2006.

30. Population census of Japan: Statistics Bureau, Ministry of Internal Affairs and Communications, Japan. http://www.stat. go.jp/data/kokusei/2015/kekka/pdf/gaiyou1.pdf. Accessed March 25, 2018

31. Tai E, Buchanan N, Townsend J, Fairley T, Moore A and Richardson LC: Health status of adolescent and young adult cancer survivors. Cancer 118: 4884-4891, 2012.

cc)(1) (9) This work is licensed under a Creative Commons International (CC BY-NC-ND 4.0) License. 